Ciência Florestal, Santa Maria, v. 21, n. 1, p. 41-52, jan.-mar., 2011

\title{
RELAÇÃO ENTRE NDVI E FLORÍSTICA EM FRAGMENTOS DE FLORESTA ESTACIONAL DECIDUAL NO VALE DO PARANÃ, GOIÁS
}

\author{
THE RELATIONSHIP BETWEEN NDVI AND FLORISTICS IN SEASONALLY DECIDUOUS \\ FOREST IN THE PARANA VALLEY, GOIAS STATE, BRAZIL
}

Potira Meirelles Hermuche ${ }^{1}$ Jeanine Maria Felfili (in memoriam) ${ }^{2}$

\section{RESUMO}

O presente trabalho tem como objetivo avaliar a relação entre o índice de vegetação NDVI e o comportamento das espécies dominantes de três fragmentos de Floresta Estacional Decidual localizados no Vale do Paranã, Goiás. Para isso, foram utilizadas imagens do sensor Landsat 7 ETM+ do ano de 2001. O estudo mostrou uma relação entre índice de vegetação NDVI das épocas de chuva e de seca e florística nos três fragmentos estudados. A análise da diferença de cobertura do dossel mostrou que as espécies exclusivas de cada fragmento apresentaram maior influência na resposta espectral do dossel por meio da análise do NDVI do que o total das espécies. O resultado da análise confirmou a classificação dos fragmentos como florestas estacionais deciduais e demonstrou que, mesmo dentro de uma mesma fisionomia, existem pequenas variações fenológicas.

Palavras-chave: Biodiversidade; florestas tropicais; índice de vegetação; Cerrado.

\begin{abstract}
The objective of this paper was to evaluate the relationship between NDVI and the patterns of the dominant species in three fragments of seasonally deciduous forest (SDF) in the Parana Valley in Goias State, Brazil. Landsat 7 ETM+ images from the year 2001 were used. The study showed a relation between NDVI and floristic patterns during the dry and rainy seasons for the three fragments studied. Exclusive species showed greater influence in the spectral response measured by NDVI than did the total species. The results confirmed the three fragments as SDF showing that even within the same physiognomy there were small phenological variations.
\end{abstract}

Keywords: Biodiversity; tropical forests; vegetation index; Cerrado.

\section{INTRODUÇÃO}

A vegetação é estudada de acordo com diferentes níveis de abordagem e a categoria de deciduidade de fenologia foliar, que é um dos principais parâmetros para a classificação em nível macro, é, em geral, assumida por avaliação visual. Nesse sentido, Meneses e Madeira Netto (2001) afirmam que o sensoriamento remoto é uma tecnologia que pode dar grandes subsídios a esse tipo de análise por meio da interação da energia eletromagnética com a planta, que está relacionada sobretudo com fatores bioquímicos e biofísicos do dossel, com a diversidade de espécies e com os componentes sazonais, responsáveis por grandes variações na cobertura vegetal (CARVALHO et al., 2007).

De todos os elementos constituintes da vegetação, a folha é o principal quando se considera o processo de interação com a energia eletromagnética, e seu comportamento pode ser observado especialmente em três regiões especificas do espectro: no visível, infravermelho próximo e infravermelho de ondas curtas (MENESES e MADEIRA NETTO, 2001). À medida que se passa da escala da folha para a

1. Geógrafa, Drạ., Universidade Federal de Goiás, Campus Samambaia, Bloco ICB4, Caixa Postal 131, CEP 74001970, Goiânia (GO). potirahermuche@gmail.com

2. † Engenheira florestal, Drª ., Departamento de Engenharia Florestal,Universidade de Brasília, Laboratório de Manejo Florestal, Caixa Postal 04357, CEP 70919-970, Brasília (DF).

Recebido para publicação em 14/07/2009 e aceito em 9/06/2010. 
escala do dossel, a variação espectral diminui, possibilitando a análise da vegetação em escala regional. Partindo desse pressuposto, surgiram os índices de vegetação derivados de imagens de satélites, como o Índice de Vegetação por Diferença Normalizada (NDVI), que se apresenta sensível a variações fenológicas do dossel da floresta, realçando suas características físicas (HUETE et al, 2002).

Em alguns casos, a diferenciação entre tipos vegetacionais, ou mesmo dentro de uma mesma fisionomia, torna-se difícil, em especial pela proximidade na resposta espectral. Tal fato é observado em algumas fitofisionomias do Cerrado, como a Floresta Estacional Decidual (FED), que é caracterizada por uma deciduidade acentuada, chegando a 90\% quando ocupa áreas rochosas de origem calcária (RIBEIRO e WALTER, 2008). Nesse caso, análises temporais são importantes subsídios na identificação e caracterização das florestas, sobretudo quando se leva em consideração as alterações ao longo do ciclo hidrológico, ou seja, quando as análises são feitas nas épocas secas e chuvosas.

Estudos recentes em fragmentos de FED têm demonstrado, principalmente, a riqueza de espécies (SILVA e SCARIOT, 2004; FELFILI e FAGG, 2007), sua similaridade com demais florestas estacionais tropicais, como a Caatinga e o Pantanal (FELFILI et al, 2007b), além de estudos de regeneração, como os de Vieira e Scariot (2006) e Sampaio et al. (2007). Entre as espécies descritas nos trabalhos citados, muitas delas raras, endêmicas e ameaçadas de extinção por terem alto valor econômico, pode-se encontrar: Cariniana estrellensis (jequitibá), Erythrina verna (mulungu), Hymenaea courbaril (jatobá), Myracrodruon urundeuva (aroeira), Tabebuia impetiginosa (ipêroxo), Amburana cearencis (cerejeira), Cedrela fissilis (cedro), Bursera leptophloeos (imburana), Cavanillesia arborea (barriguda). Além dessas, são encontradas ainda espécies espinhosas, urticantes e cactáceas.

Mesmo com as iniciativas de pesquisa, é grande a deficiência de informações acerca dessa fitofisionomia, fato observado em trabalhos como o Mapa de Vegetação do IBGE (2004), que classifica as FED localizadas no Vale do Paranã como área de contato. Esse exemplo demonstra a importância de estudos específicos acerca dessa fitofisionomia em maior escala.

O objetivo do trabalho é avaliar a relação entre o índice de vegetação NDVI, das épocas de seca e chuva, e o comportamento das espécies dominantes em três fragmentos de FED localizados no Vale do Paranã, região nordeste de Goiás.

\section{MATERIAL E MÉTODOS}

No presente estudo, foram analisados três fragmentos de FED localizados Vale do Paranã, região nordeste de Goiás, nos municípios de Monte Alegre de Goiás (Faz. Cordeirinho), Guarani de Goiás (Faz. Forquilha) e Iaciara (Faz. Sabonete) Figura 1.

Como base, foram utilizadas duas cenas do sensor LANDSAT 7 ETM+, adquiridas na página eletrônica do Instituto Nacional de Pesquisas Espaciais - INPE (http://www.dgi.inpe. br/cdsr/), com datas de passagem das épocas seca e chuvosa, conforme Tabela 1. As cenas foram georreferenciadas com base em imagens geocover (imagens ortorretificadas do Landsat ETM+, disponíveis na página eletrônica da NASA - http:// www.glcf.umiacs.umd.edu/portal/geocover/), no sistema de projeção UTM (Zona 23 Sul) e referencial geodésico WGS 84, com erro quadrático médio (RMS) inferior a 0,5 pixels.

A definição dos limites dos fragmentos foi feita tomando-se como referência pontos de campo (conduzido nos dias 25 e 26 de outubro de 2008) e observação visual nas imagens de satélite. Dados topográficos do SRTM (Shuttle Radar Topography Mission), com resolução de 90 metros (NASA, 2008), também foram utilizados como subsídio. Pode-se assumir que a defasagem entre as datas de passagem das imagens e o trabalho de campo não interferiu na delimitação dos fragmentos, pois estes estão situados sobre afloramentos rochosos e topografia acidentada, os quais funcionam como barreiras naturais para o avanço das atividades agropecuárias.

A análise da diferença de cobertura do dossel dos três fragmentos, nas épocas de chuva e de seca, foi feita com base em imagens índice NDVI, derivadas das imagens de satélite originais por meio da razão entre a diferença da medida da reflectância nos canais do infravermelho próximo e vermelho e a soma desses, expresso pela seguinte equação (HUETE et al., 2002):

NDVI $=($ NIR-vermelho $) /($ NIR + vermelho $)$ Em que: NIR = infravermelho próximo

Ci. Fl., v. 21, n. 1, jan.-mar., 2011 


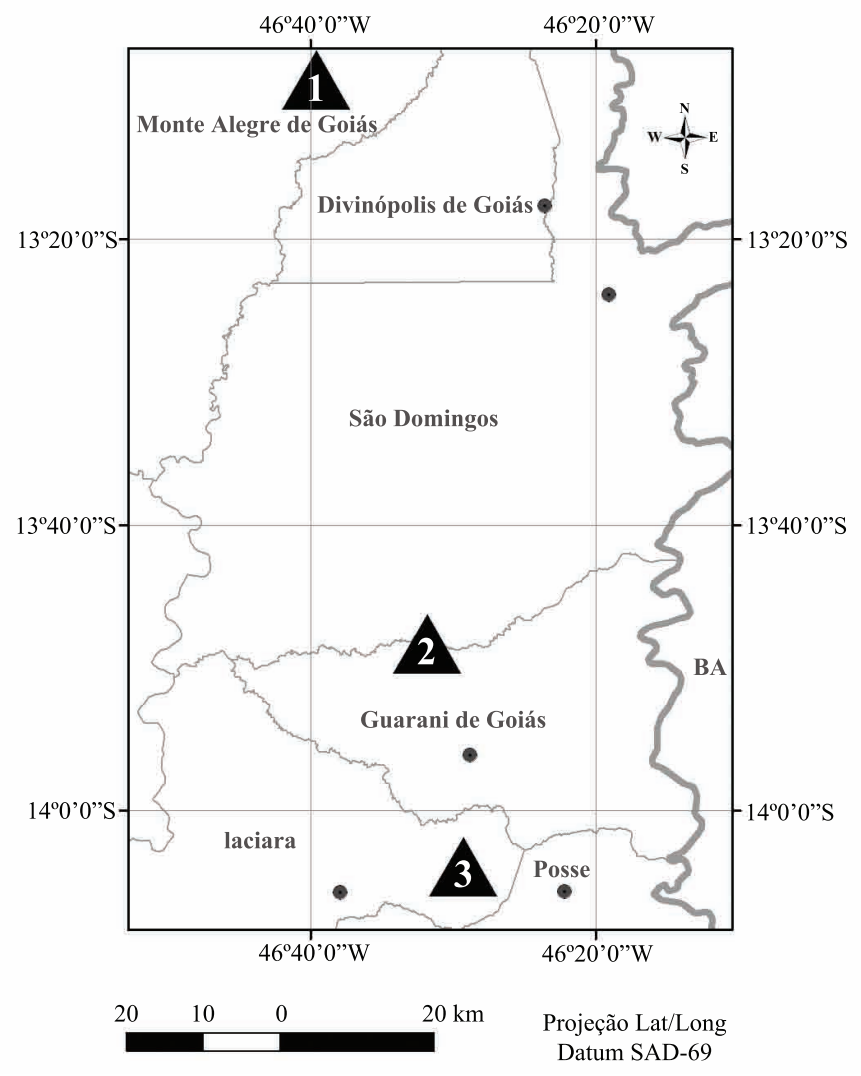
Localização das áreas de estudo no Estado de Goiás

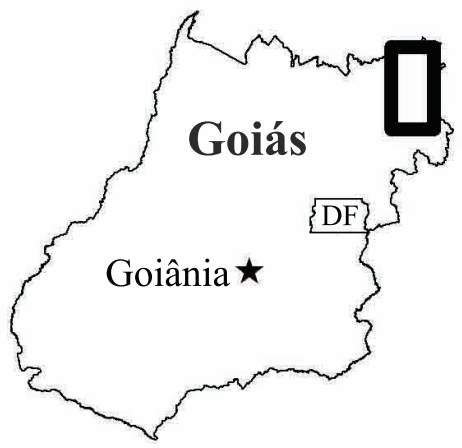

\section{Legenda:}

- Limites municipais

- Limites estadual

- Sedes municipais

$\Delta$ Fragmentos estudados

1- Fazenda Cordeirinho

2 - Fazenda Forquilha

3 - Fazenda Sabonete

FIGURA 1: Localização dos fragmentos no Vale do Paranã, Goiás.

FIGURE 1: Fragment location in the Parana Valley in Goias State, Brazil.

TABELA 1: Cenas do sensor Landsat ETM+ utilizadas no estudo.

TABLE 1: Landsat ETM+ scenes used in the study.

\begin{tabular}{c|c|c|c}
\hline \multicolumn{2}{c|}{ Cena 221/069 } & \multicolumn{2}{c}{ Cena 220/070 } \\
\hline Chuva & Seca & Chuva & Seca \\
\hline $01 / 05 / 2001$ & $20 / 07 / 2001$ & $24 / 04 / 2001$ & $29 / 07 / 2001$ \\
\hline
\end{tabular}

As estatísticas dos valores de NDVI de cada fragmento foram calculadas no software ENVI 4.3, utilizando-se os limites anteriormente definidos como regiões de interesse para o cálculo.

Após a diferenciação dos três fragmentos partindo de imagens-índice, foram utilizados dados florísticos de 75 parcelas permanentes $(25$ em cada fragmento), inventariados no âmbito do projeto "Estratégias para conservação e manejo da biodiversidade em fragmentos de Florestas Semidecíduas" por pesquisadores da Universidade de Brasília por meio de financiamento do MMA PROBIO. O método utilizado para o levantamento foi baseado em amostragem de faixas de $20 \mathrm{~m}$ de largura perpendiculares ao gradiente longitudinal, subdivididas em parcelas de $20 \times 20 \mathrm{~m}\left(400 \mathrm{~m}^{2}\right)$, das quais foram sorteadas aleatoriamente 25 parcelas em cada fragmento, totalizando um hectare em cada fragmento. Em cada unidade amostral, foram mensurados os valores de circunferência na altura do peito (CAP) e altura total, além da identificação das espécies em campo ao longo de excursões realizadas nas estações seca e chuvosa. Os principais parâmetros avaliados foram o número de espécies, número de gêneros, diversidade (índice de Shannon), número de famílias e densidade (indivíduos por hectare) (NASCIMENTO et al., 2004; NASCIMENTO, 2005; FELFILI et al., 2007a).

Os dados do levantamento florístico foram acrescidos das características de fenologia foliar de cada espécie no que diz respeito à deciduidade, baseado em Lorenzi (1998; 2000) e Carvalho (2003; 2006). O objetivo dessa análise foi o entendimento do comportamento espectral do dossel em função das características das espécies encontradas nos fragmentos. 


\section{RESULTADOS E DISCUSSÃO}

Após a definição dos limites dos três fragmentos estudados, a análise do dossel por meio de imagens índice NDVI proporcionou a identificação de diferenças na cobertura vegetal entre os fragmentos, nas estações seca e chuvosa. Quanto mais próximo à cor branca, mais fotossinteticamente ativa é a vegetação (Figura 2).

A análise das estatísticas dos valores de NDVI de cada fragmento (Figuras 3 a 5) mostrou que o fragmento da Faz. Cordeirinho apresenta o maior valor de NDVI na época seca, podendose inferir que este possui maior quantidade de vegetação verde e/ou maior cobertura do dossel na época seca. Em seguida encontra-se o fragmento da Faz. Sabonete e, por último, a Faz. Forquilha.

Em relação à época chuvosa, o fragmento que apresenta maior valor médio de NDVI é o da Faz. Sabonete, podendo-se inferir que este possui a maior quantidade de vegetação verde e/ou maior cobertura dossel nesta época. Em segundo lugar está o fragmento da Faz. Cordeirinho e, por último, o da Faz. Forquilha.

Em resumo, uma análise dos valores de NDVI médio de cada fragmento nas épocas seca e chuvosa indica que o fragmento que apresenta menor índice de vegetação médio, tanto na seca como na chuva, é o localizado na Faz. Forquilha. (Figura 6). Esses valores corroboram com o que foi visto em campo, onde, na mesma época visitada, os três fragmentos apresentaram-se distintos no que diz respeito à fenologia foliar.

Os dados florísticos de cada fragmento (Tabela 2) indicaram a presença de quarenta espécies no fragmento da Faz. Sabonete, 55 no fragmento da Faz. Forquilha e 51 espécies no fragmento da Faz. Cordeirinho. O fragmento localizado na Faz. Forquilha apresentou os maiores valores de índice de diversidade (3,2, contra 2,8 para a Faz. Sabonete e 3,0 para a Faz. Cordeirinho), gênero (42, contra 31 para a Faz. Sabonete e 41 para a Faz. Cordeirinho) e família (23, contra 22 para a Faz. Sabonete e 21 para a Faz. Cordeirinho).
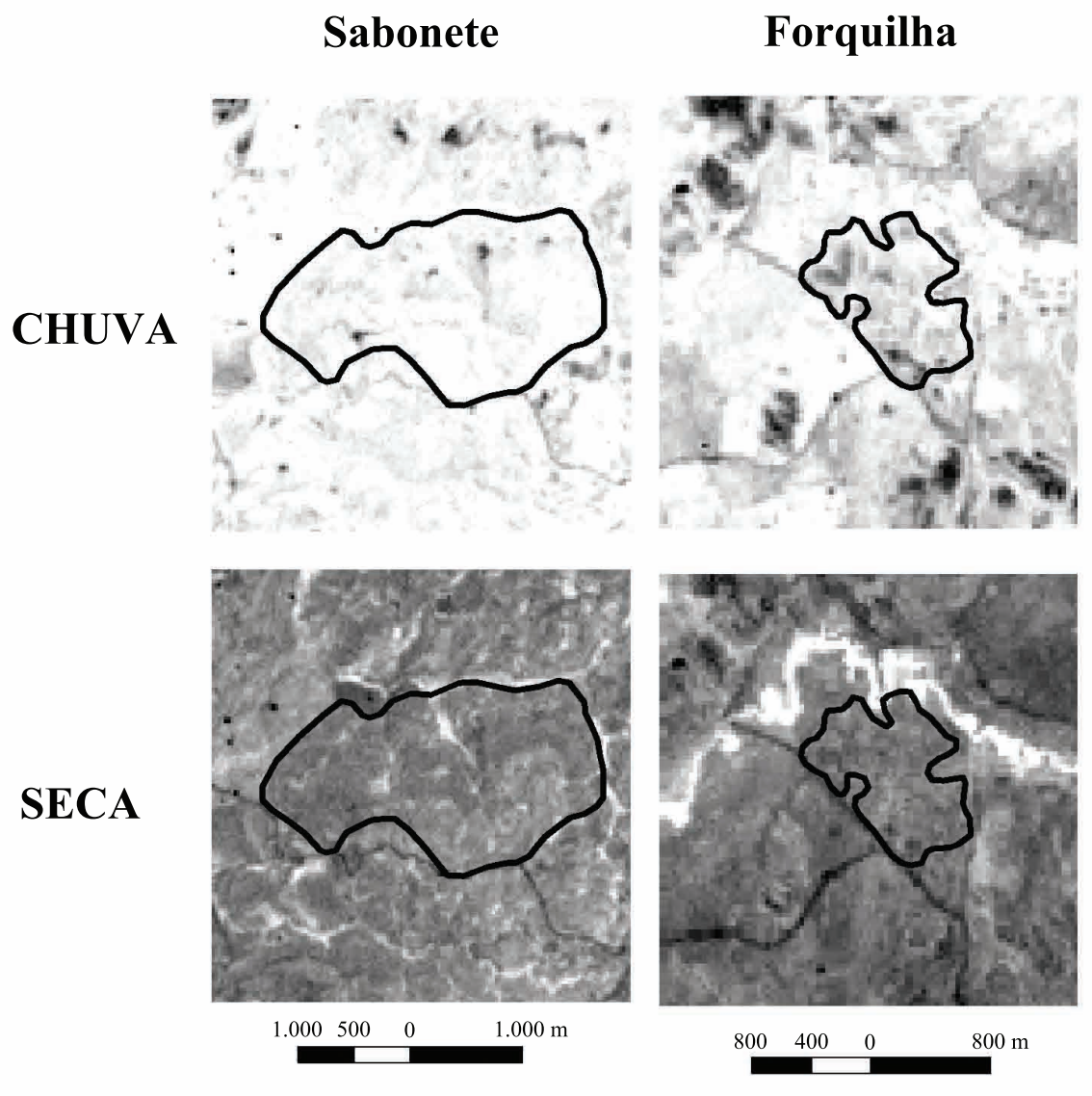

\section{Cordeirinho}
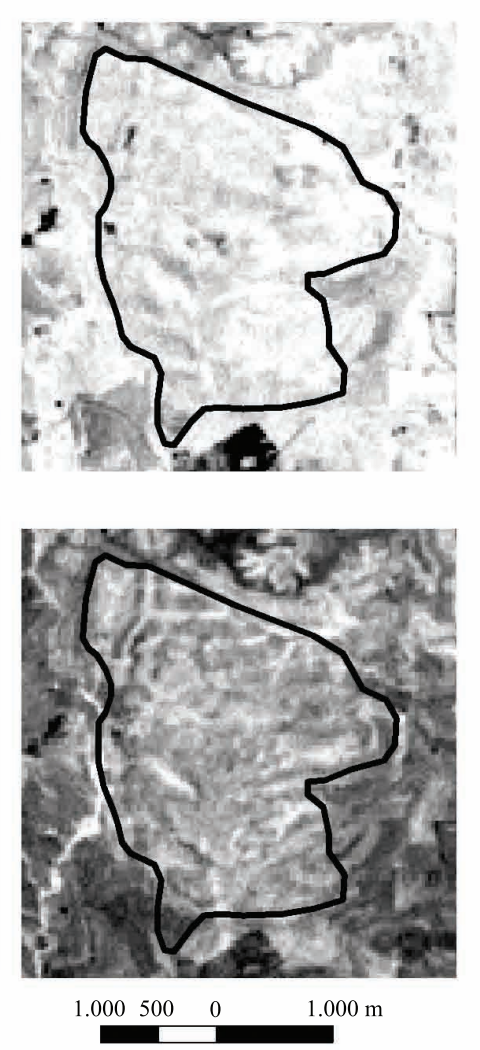

FIGURA 2: Diferença de cobertura do dossel nas épocas de chuva e seca dos três fragmentos de FED.

FIGURE 2: The difference in canopy covering during the dry and wet seasons for the three fragments of SDF. 

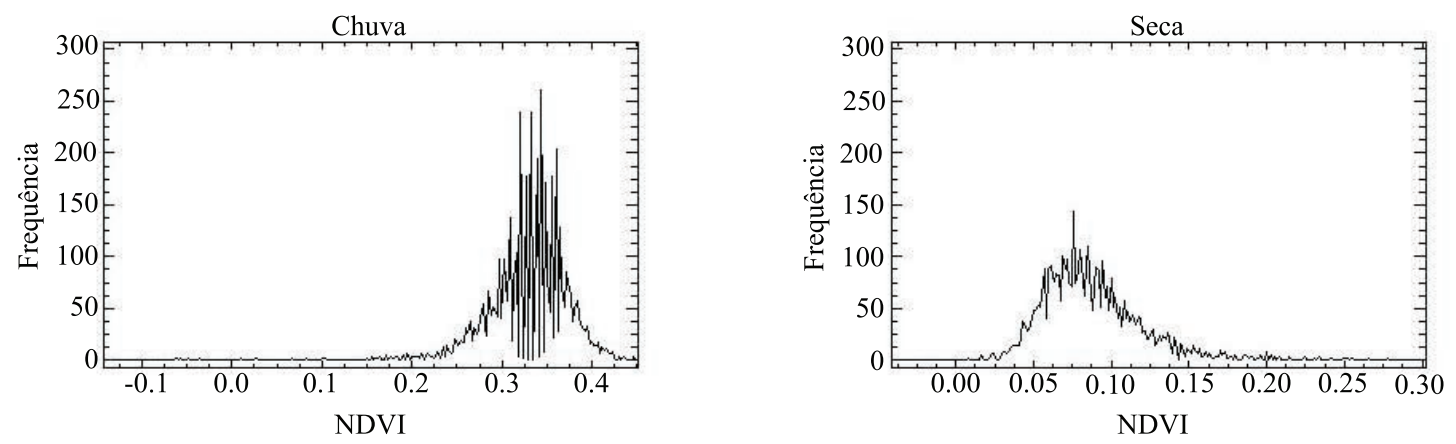

FIGURA 3: Frequência do NDVI no fragmento da Faz. Sabonete, em Iaciara.

FIGURE 3: NDVI frequency in the Sabonete fragment at Iaciara.
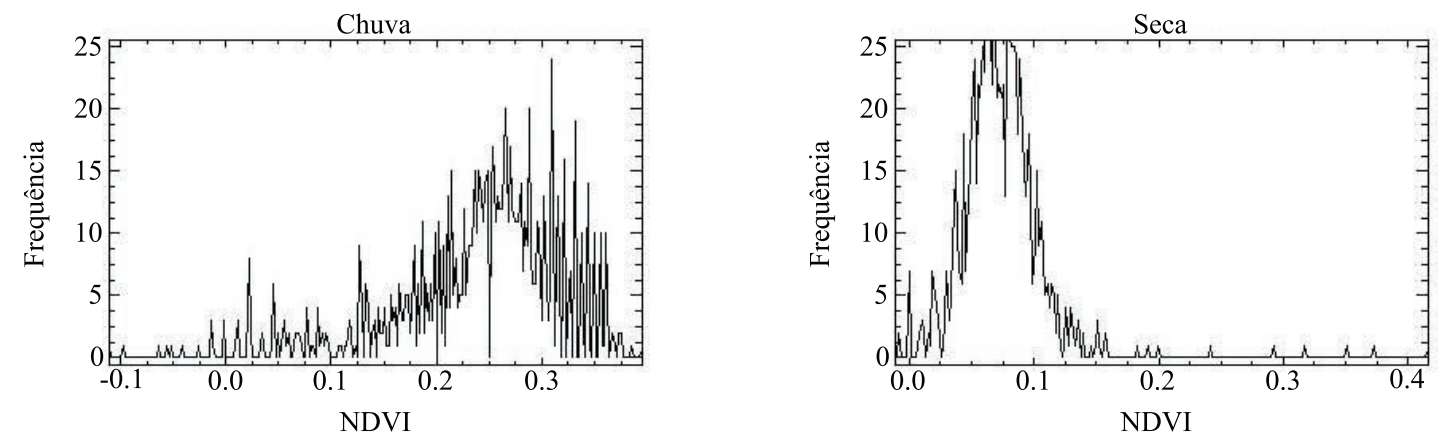

FIGURA 4: Freqüência do NDVI no fragmento da Faz. Forquilha, em Guarani de Goiás.

FIGURE 4: NDVI frequency in the Forquilha fragment at Guarani de Goias.
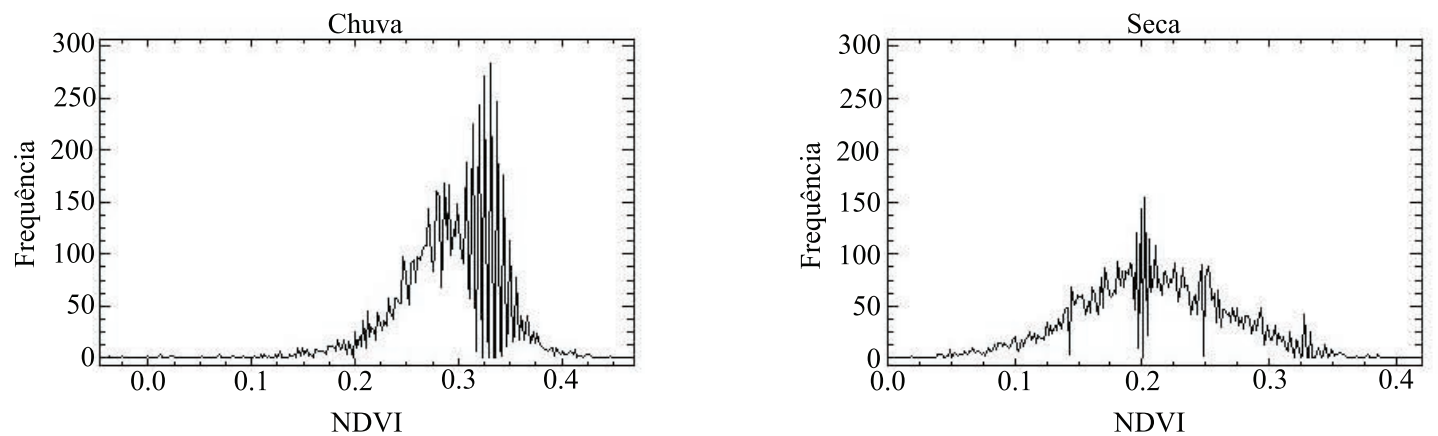

FIGURA 5: Freqüência do NDVI no fragmento da Faz. Cordeirinho, em Monte Alegre de Goiás.

FIGURE 5: NDVI frequency in the Cordeirinho fragment at Monte Alegre de Goias.

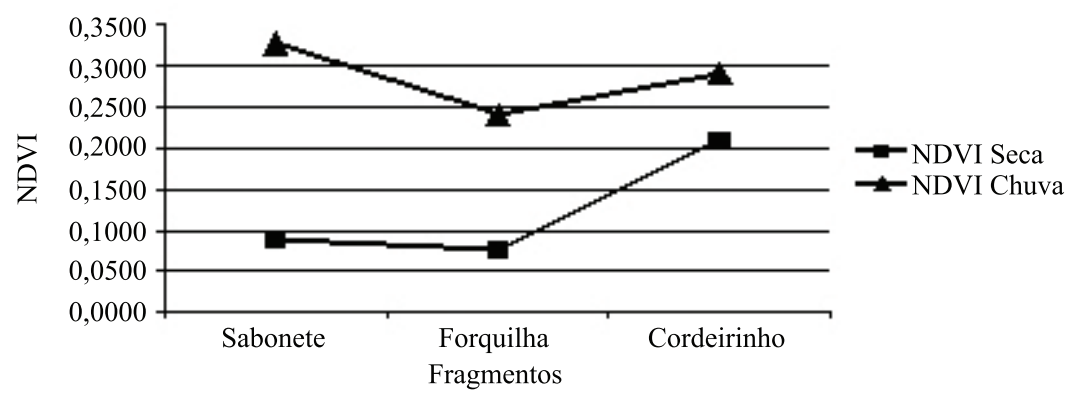

FIGURA 6: NDVI médio nas épocas de chuva e seca dos três fragmentos de FED.

FIGURE 6: NDVI frequency in the Cordeirinho fragment at Monte Alegre de Goias. 
TABELA 2: Lista de espécies encontradas na Faz. Sabonete, Faz. Forquilha e Faz. Cordeirinho .

TABLE 2: List of species found in the Sabonete fragment, Forquilha fragment and Cordeirinho fragment.

Família/Espécies

\begin{tabular}{|c|c|c|c}
\multicolumn{2}{|c|}{ Fazendas/Fragmentos } & \multirow{2}{*}{$\begin{array}{c}\text { Fenologia } \\
\text { Foliar }\end{array}$} \\
\cline { 1 - 2 } Sabonete & Forquilha & Cordeirinho & Foling \\
\hline
\end{tabular}

ANARCADIACEAE

Astronium fraxinifolium Scott ex Spreng

Myracrodruon urundeuva Fr. Allem.

Schinopsis brasiliensis Engl.

Spondias mombin L.

ANNONACEAE

Cardiopetalum calophyllum Schtdl

Oxandra reticulata Maas

Semidecídua

APOCYNACEAE

Aspidosperma parvifolium A. DC.

Aspidosperma pyrifolium Mart.

Aspidosperma subincanum Mart.

Aspidosperma sp.

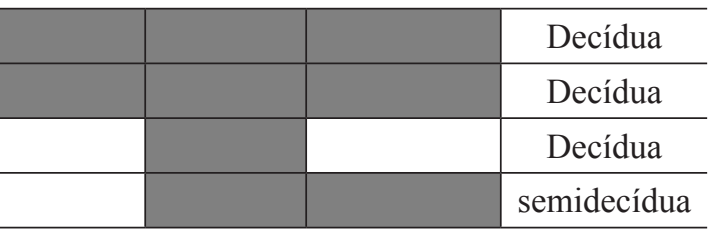

ARALIACEAE

Sciadodendron excelsum Grisseb

BIGNONIACEAE

Jacaranda brasiliana (Lam.) Pers

Jacaranda sp.

Tabebuia impetiginosa (Mart. Ex DC.) Standl

Tabebuia roseo-alba (Ridley) Sandw.

Tabebuia serratifolia (Vahl) G. Nicholson

Decídua

BOMBACACEAE

Cavanillesia arbórea (Willd.) K. Schum

Chorisia speciosa A. St. Hil.

Eriotheca gracilipes (K. Schum) A. Robyns

Pseudobombax tomentosum (Mart. \& Zucc) A. Robyns

\begin{tabular}{l|l|l|c} 
& & & Semidecídua \\
\hline & & & Decídua \\
\hline
\end{tabular}

BORAGINACEAE

Cordia trichotoma (Vell.) Arrab. Ex Steud

BURSERACEAE

Commiphora leptophloeos (Mart.) J.B.Gillett

Commiphora sp.

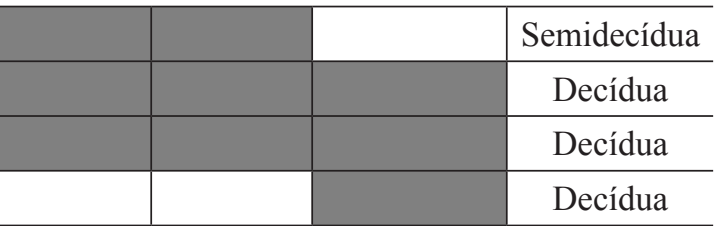

CELASTRACEAE

Maytenus sp.

\begin{tabular}{l|l|l|l} 
& & & Decídua \\
\hline
\end{tabular}

COMBRETACEAE

Combretum duarteanum Camb.

Combretum sp.

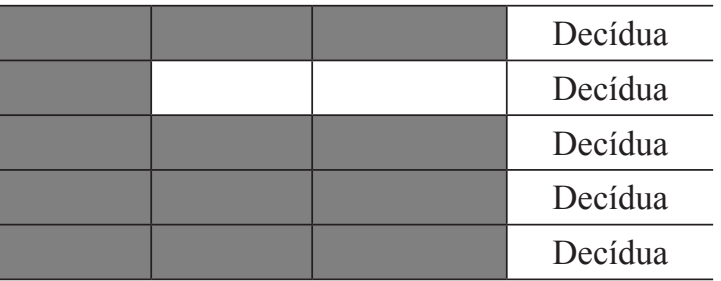

ERYTHROXYLACEAE

Erythroxylum daphnites Mart.

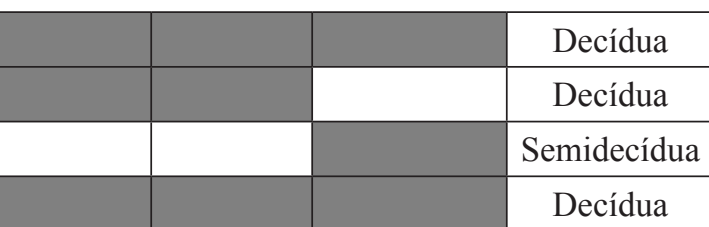

Decídua

Continua...

Ci. Fl., v. 21, n. 1, jan.-mar., 2011 
TABELA 2: Continuação...

TABLE 2: Continued...

\begin{tabular}{|c|c|c|c|c|}
\hline \multirow{2}{*}{ Família/Espécies } & \multicolumn{3}{|c|}{ Fazendas/Fragmentos } & \multirow{2}{*}{$\begin{array}{l}\text { Fenologia } \\
\text { Foliar }\end{array}$} \\
\hline & Sabonete & Forquilha & Cordeirinho & \\
\hline \multicolumn{5}{|l|}{ EUPHORBIACEAE } \\
\hline Cnidoscolus vitifolius (Miller) Pohl & & & & Decídua \\
\hline Sapium glandulatum (Vell.) Pax. & & & & Decídua \\
\hline \multicolumn{5}{|l|}{ FLACOURTIACEAE } \\
\hline Casearia grandiflora Camb. & & & & Decídua \\
\hline Casearia rupestris Eichler & & & & Semidecídua \\
\hline \multicolumn{5}{|l|}{ LEGUMINOSAE-CAESALPINOIDEAE } \\
\hline Bauhinia membranaceae Benth. & & & & Decídua \\
\hline Bauhinia ungulata $\mathrm{L}$. & & & & Decídua \\
\hline Senna spectabilis (Shrad.) Irwin \& Barneby & & & & Decídua \\
\hline \multicolumn{5}{|l|}{ LEGUMINOSAE MIMOSOIDEAE } \\
\hline Acacia paniculata Willd. & & & & Semidecídua \\
\hline Acacia polyphylla DC. & & & & Semidecídua \\
\hline Anadenanthera colubrina (Vell.) Brenan var. colubrina & & & & Decídua \\
\hline $\begin{array}{l}\text { Anadenanthera colubrina (Vell.) Brenan var. cebil (Griseb.) } \\
\text { Altschul }\end{array}$ & & & & Decídua \\
\hline Anadenanthera peregrina (Benth.) Reiss var. falcata & & & & Decídua \\
\hline Chloroleucon tenuiflorum Benth. & & & & Decídua \\
\hline Enterolobium contortisiliquum (Vell.) Morong. & & & & Decídua \\
\hline Piptadenia gonoacantha (Mart.) Macbr. & & & & Semidecídua \\
\hline Samanea tubulosa (Benth.) Barneby \& J.W. Grimes & & & & Decidua \\
\hline \multicolumn{5}{|l|}{ LEGUMINOSAE PAPILIONOIDEAE } \\
\hline Amburana cearensis (Fr. Allem.) A. A. Smith & & & & Decídua \\
\hline Diptychandra aurantiaca Tul. & & & & Decídua \\
\hline Erythrina verna Vell. & & & & Decídua \\
\hline Lonchocarpus montanus Tozzi & & & & Semidecídua \\
\hline Machaerium aculeatum Raddi & & & & Decídua \\
\hline Machaerium acutifolium Vogel & & & & Semidecídua \\
\hline Machaerium opacum Vogel & & & & Decídua \\
\hline Machaerium scleroxylon Tul. & & & & Decídua \\
\hline Machaerium stiptatum (DC.) Vogel & & & & Semidecídua \\
\hline Machaerium sp. & & & & Semidecídua \\
\hline Platypodium elegans Vogel & & & & Semidecídua \\
\hline Swartzia multijuga Vog. & & & & Decídua \\
\hline \multicolumn{5}{|l|}{ MALPIGHIACEAE } \\
\hline \multicolumn{5}{|l|}{ Indet. (1sp.) } \\
\hline \multicolumn{5}{|l|}{ MELIACEAE } \\
\hline Cedrella fissilis Vell. & & & & Decídua \\
\hline
\end{tabular}

Continua... 
TABELA 2: Continuação...

TABLE 2: Continued...

\begin{tabular}{|c|c|c|c|c|}
\hline \multirow{2}{*}{ Família/Espécies } & \multicolumn{3}{|c|}{ Fazendas/Fragmentos } & \multirow{2}{*}{$\begin{array}{c}\text { Fenologia } \\
\text { Foliar }\end{array}$} \\
\hline & Sabonete & Forquilha & Cordeirinho & \\
\hline Trichilia catigua A Juss & & & & Semidecídua \\
\hline Trichilia hirta $\mathrm{L}$. & & & & Semidecídua \\
\hline \multicolumn{5}{|l|}{ Indet. (1sp.) } \\
\hline \multicolumn{5}{|l|}{ MORACEAE } \\
\hline Ficus pertusa L. & & & & Semidecídua \\
\hline Maclura tinctoria L.D. Don ex Steud. & & & & Decídua \\
\hline \multicolumn{5}{|l|}{ MYRTACEAE } \\
\hline Campomanesia xanthocarpa Berg. & & & & Decídua \\
\hline Eugenia dysenterica DC & & & & Decídua \\
\hline Psidium sartorianum (Berg.) Nied. & & & & Perenifólia \\
\hline \multicolumn{5}{|l|}{ NYCTAGINACEAE } \\
\hline Guapira paraguayensis (Heimerl) Lundell & & & & Semidecídua \\
\hline \multicolumn{5}{|l|}{ OLACACEAE } \\
\hline Ximenia americana L. & & & & Decídua \\
\hline \multicolumn{5}{|l|}{ POLYGONACEAE } \\
\hline Triplaris garderiana Wedd. & & & & Decídua \\
\hline \multicolumn{5}{|l|}{ RHAMNACEAE } \\
\hline Rhamnidium elaeocarpum Reiss & & & & Decídua \\
\hline \multicolumn{5}{|l|}{ RUBIACEAE } \\
\hline Alibertia macrophylla K. Schum. & & & & Semidecídua \\
\hline Guettarda viburnoides Cham \& Schtdl. & & & & Semidecídua \\
\hline Tocoyena formosa (Cham \& Schtdl.) Schum. & & & & Decídua \\
\hline \multicolumn{5}{|l|}{ RUTACEAE } \\
\hline Zanthoxylum riedelianum Engl. & & & & Decídua \\
\hline \multicolumn{5}{|l|}{ SAPINDACEAE } \\
\hline Dilodendron bipinnatum Radlk. & & & & Semidecídua \\
\hline Talisia esculenta (A. St.-Hil.) Radlk. & & & & Perenifolia \\
\hline \multicolumn{5}{|l|}{ SAPOTACEAE } \\
\hline Micropholis venulosa (Mart. \& Eichl.) Pierre & & & & Semidecídua \\
\hline \multicolumn{5}{|l|}{ SIMAROUBACEAE } \\
\hline Simarouba amara Aubl. & & & & Semidecídua \\
\hline \multicolumn{5}{|l|}{ STERCULIACEAE } \\
\hline Guazuma ulmifolia Lam. & & & & Semidecídua \\
\hline Sterculia striata St. Hil \& Naud. & & & & Decídua \\
\hline \multicolumn{5}{|l|}{ TILIACEAE } \\
\hline Luehea candicans Mart. & & & & Semidecídua \\
\hline \multicolumn{5}{|l|}{ VOCHYSIACEAE } \\
\hline Callisthene fasciculata Mart. & & & & Decídua \\
\hline
\end{tabular}

Fonte: Nascimento (2005). 
O fragmento da Faz. Forquilha apresentou 19 espécies exclusivas, enquanto os da Faz. Cordeirinho e Sabonete apresentaram 16 e quatro espécies exclusivas respectivamente. As espécies exclusivas identificadas na Faz. Forquilha foram: Schinopsis brasiliensis Engl.; Cardiopetalum calophyllum Schtdl; Sciadodendron excelsum Grisseb; Commiphora sp.; Maytenus sp.; Cnidoscolus vitifolius (Miller) Pohl; Sapium glandulatum (Vell.) Pax; Senna spectabilis (Shrad.) Irwin \& Barneby; Amburana cearensis (Fr. Allem.) A. A. Smith; Diptychandra aurantiaca Tul.; Machaerium aculeatum Raddi; Machaerium opacum Vogel; Cedrella fissilis Vell.; Trichilia catigua A Juss; Trichilia hirta L.; Indet. (1sp.); Ficus pertusa L.; Eugenia dysenterica DC; Simarouba amara Aubl. As identificadas na Faz. Cordeirinho foram: Aspidosperma sp.; Eriotheca gracilipes (K. Schum) A. Robyns; Casearia grandiflora Camb.; Anadenanthera colubrina (Vell.) Brenan var. cebil (Griseb.) Altschul; Anadenanthera peregrina (Benth.)Reiss var.falcata; Chloroleucontenuiflorum Benth.; Samanea tubulosa (Benth.) Barneby \&
J.W. Grimes; Swartzia multijuga Vog.; Maclura tinctoria L.D. Don ex Steud.; Campomanesia xanthocarpa Berg.; Psidium sartorianum (Berg.) Nied.; Guapira paraguayensis (Heimerl) Lundell; Triplaris garderiana Wedd.; Alibertia macrophylla K. Schum.; Zanthoxylum riedelianum Engl.; Talisia esculenta (A. St.-Hil.) Radlk. As identificadas na Faz. Sabonete foram: Jacaranda sp.; Casearia rupestris Eichler; Machaerium sp.; Micropholis venulosa (Mart. \& Eichl.) Pierre.

Baseado nos dados de florística, a distribuição das espécies conforme a fenologia foliar mostra que, no que diz respeito ao total das espécies, os três fragmentos possuem aproximadamente a mesma porcentagem (Tabela 3). Quando a análise é feita apenas em relação às espécies exclusivas, o fragmento da Faz. Sabonete possui 7,9\% das espécies que o compõem exclusivas, a Faz. Forquilha 35,8\% e a Faz. Cordeirinho 33,3\%, indicando que além de diferenças na porcentagem de espécies exclusivas, também existe variação no que diz respeito à fenologia foliar dessas espécies exclusivas em cada fragmento, como mostra a Tabela 4.

TABELA 3: Número de espécies conforme a fenologia foliar dos três fragmentos de FED.

TABLE 3: Number of species according to leaf phenology of the three fragments of seasonally deciduous forest.

\begin{tabular}{c|c|c|c|c|c|c}
\hline \multirow{2}{*}{ Fenologia foliar* } & \multicolumn{4}{|c}{ Fazendas/fragmentos } \\
\cline { 2 - 7 } & \multicolumn{2}{|c|}{ Sabonete } & \multicolumn{2}{|c}{ Forquilha } & \multicolumn{2}{c}{ Cordeirinho } \\
\cline { 2 - 7 } & N. & $\%$ & N. & $\%$ & N. & $\%$ \\
\hline Semidecíduas & 14 & 35,9 & 18 & 34,0 & 15 & 29,4 \\
\hline Decíduas & 25 & 64,1 & 35 & 66,0 & 34 & 66,7 \\
\hline Perenifólias & - & - & - & - & 2 & 3,9 \\
\hline Total & 39 & 100,0 & 53 & 100,0 & 51 & 100,0 \\
\hline
\end{tabular}

*Foram excluídas as espécies indeterminadas

TABELA 4: Número de espécies exclusivas conforme a fenologia foliar dos três fragmentos de FED.

TABLE 4: Number of exclusive species according to leaf phenology of the three fragments of seasonally deciduous forest.

\begin{tabular}{|c|c|c|c|c|c|c|}
\hline \multirow{3}{*}{ Fenologia foliar } & \multicolumn{6}{|c|}{ Fazendas/fragmentos } \\
\hline & \multicolumn{2}{|c|}{ Sabonete } & \multicolumn{2}{|c|}{ Forquilha } & \multicolumn{2}{|c|}{ Cordeirinho } \\
\hline & N. & $\%$ & $\mathrm{~N}$. & $\%$ & N. & $\%$ \\
\hline Semidecíduas & 3 & 75,0 & 6 & 31,6 & 3 & 18,8 \\
\hline Decíduas & 1 & 25,0 & 12 & 63,2 & 11 & 68,8 \\
\hline Perenifólias & - & & - & - & 2 & 12,5 \\
\hline Total & 4 & 100,0 & 18 & 100,0 & 16 & 100,0 \\
\hline \% Em relação ao & \multirow{2}{*}{$7,90 \%$} & \multirow{2}{*}{-} & \multirow{2}{*}{$35,80 \%$} & \multirow{2}{*}{-} & \multirow{2}{*}{$33,30 \%$} & \multirow{2}{*}{-} \\
\hline Total de espécies & & & & & & \\
\hline
\end{tabular}


A observação conjunta dos dados de NDVI e espécies totais (Figura 7) e NDVI e espécies exclusivas (Figura 8) nos três fragmentos estudados mostra que a fenologia foliar e número de espécies exclusivas em cada fragmento tem grande influência na resposta espectral do dossel quando analisado por meio do índice de vegetação NDVI.

No que diz respeito às espécies exclusivas, no fragmento da Faz. Sabonete, o alto valor de NDVI na época chuvosa pode ser explicado pelo grande número de espécies semidecíduas, as quais não perdem totalmente suas folhas durante a estação seca. No fragmento da Faz. Forquilha, os valores de NDVI, tanto da seca quanto da chuva, são os menores, o que pode ser explicado pela grande quantidade de espécies decíduas (o maior número dessas espécies pertencem a esse fragmento). No fragmento da Faz. Cordeirinho, apesar da grande quantidade de espécies decíduas, as espécies perenifólias fazem com que o NDVI na época da seca seja alto.

$\mathrm{O}$ fragmento que apresentou os menores valores de NDVI tanto na seca quanto na chuva foi o que possuía os maiores valores de diversidade, número de gêneros e famílias (Faz. Forquilha). Essa relação está de acordo com o trabalho realizado por Oindo e Skidmore (2002) que avaliaram a relação entre a variabilidade do NDVI e a riqueza de espécies

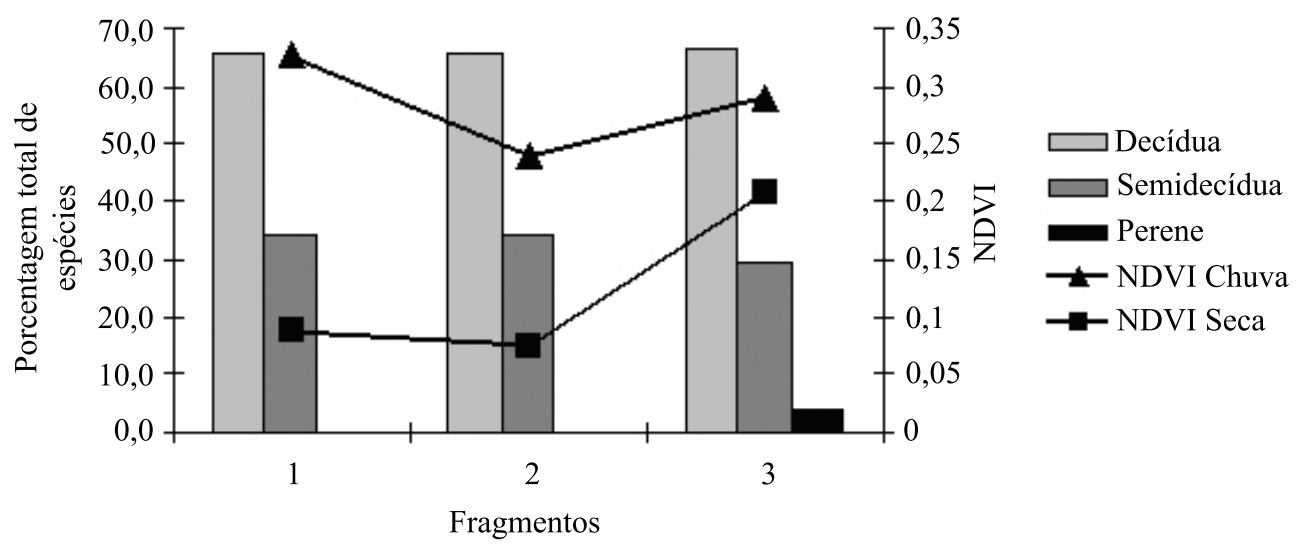

FIGURA 7: Porcentagem de espécies exclusivas conforme a fenologia foliar e NDVI por localidade (Fragmento 1 = Sabonete; Fragmento $2=$ Forquilha; Fragmento 3 = Cordeirinho).

FIGURE 7: Percentage of exclusive species according to leaf phenology and NDVI in each location (Fragment 1= Sabonete; Fragment 2=Forquilha; Fragment 3=Cordeirinho).

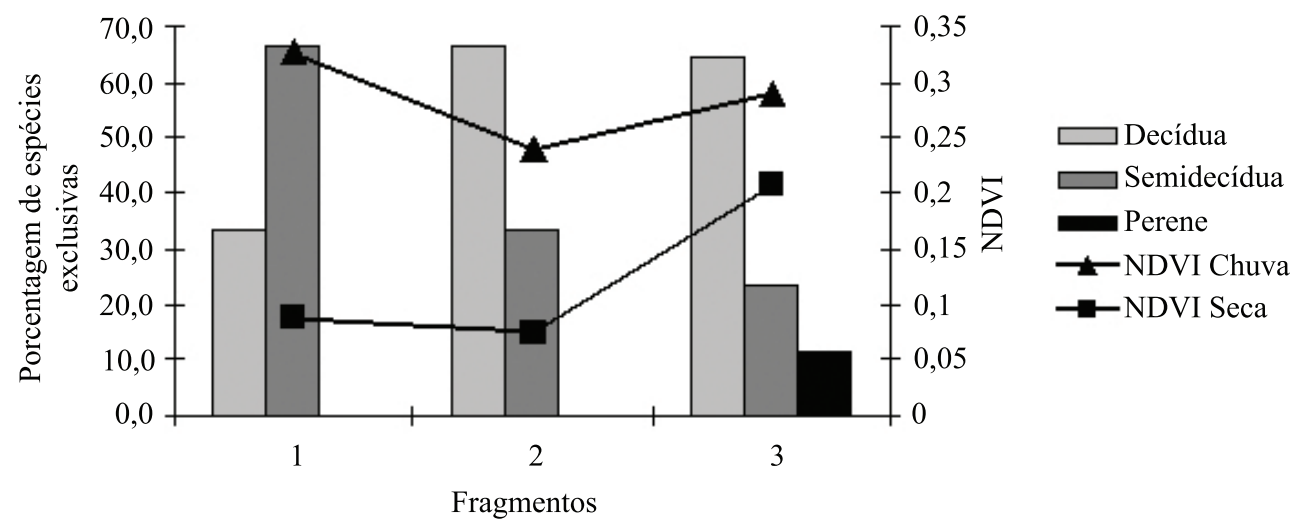

FIGURA 8: Porcentagem do total de espécies conforme fenologia foliar e NDVI por localidade (Fragmento 1 = Sabonete; Fragmento 2 = Forquilha; Fragmento 3 = Cordeirinho) .

FIGURE 8: Percentage of the total of species according to leaf phenology and NDVI in each location (Fragment 1= Sabonete; Fragment 2=Forquilha; Fragment 3=Cordeirinho).

Ci. Fl., v. 21, n. 1, jan.-mar., 2011 
da flora no Quênia (composta sobretudopela savana africana).

Uma outra indicação que pode ser deduzida é que a produtividade da floresta e a diversidade de mamíferos, herbívoros e pássaros é mais alta na Faz. Cordeirinho. De acordo com Hurlbert e Haskel (2003), Bailey et al. (2004) e Pettorelli et al. (2005), a diversidade ecológica e produtividade da floresta estão diretamente associadas com o incremento nos valores de NDVI.

Tais afirmações, além da comprovação da influência das espécies exclusivas no valor de NDVI, poderão ser comprovadas, inclusive estatisticamente, quando houver disponibilidade de imagens multitemporais e com resolução espacial centimétrica. Com essas imagens, será possível conduzir estudos em nível de parcela, envolvendo análises espectrais de cada indivíduo.

\section{CONCLUSÃO}

Os resultados do estudo mostraram uma boa relação entre o índice de vegetação NDVI derivado de imagens Landsat 7 ETM+, das épocas de chuva e de seca, e florística dos três fragmentos estudados. Estes confirmam a classificação dessas florestas como estacionais deciduais e demonstram que, mesmo dentro de uma mesma fisionomia, existem variações fenológicas.

Aparentemente a fenologia das espécies exclusivas determina a variação nos valores de NDVI, sendo que as espécies exclusivas de cada fragmento apresentaram maior interferência na resposta espectral do dossel do que o total das espécies.

Estudos futuros podem incluir análises multitemporais em variados anos, além do número de indivíduos em cada parcela, para uma análise mais detalhada da relação entre NDVI e as características fenológicas das espécies que compõem os fragmentos.

Como o NDVI está diretamente relacionado com a produtividade da vegetação, existem várias possibilidades de aplicação em propostas ecológicas, uma vez que o índice permite derivar informações sobre a distribuição temporal e espacial de comunidades, biomassa, fluxo de $\mathrm{CO}_{2}$ e até mesmo degradação. A relação entre variabilidade na composição de espécies e NDVI possibilita ainda o uso desse índice para monitorar quaisquer alterações antrópicas ou naturais na dinâmica da composição e distribuição das espécies nos fragmentos de FED.

\section{REFERÊNCIAS BIBLIOGRÁFICAS}

BAILEY, S. A. et al. Primary productivity and species richness: relationships among functional guilds, residency groups and vagility classes at multiple spatial scales. Ecography, v. 27, p. 207217, 2004.

CARVALHO, A. P. F. et al. Variações sazonais nas concentrações de pigmentos e nutrientes em folhas de espécies de cerrado com diferentes estratégias fenológicas. Revista Brasileira de Botânica, v. 30, n. 1, p. 19-27, jan.-mar. 2007.

CARVALHO, P. E. R. Espécies arbóreas brasileiras. Volume 1 Brasília: Embrapa Informação Tecnológica; Colombo/PR: Embrapa Florestas, 2003. 1039 p.

CARVALHO, P. E. R. Espécies arbóreas brasileiras. Volume 2 Brasília: Embrapa Informação Tecnológica; Colombo/PR: Embrapa Florestas, 2006. $627 \mathrm{p}$.

FELFILI, J. M. et al. Floristic composition and community structure of a seasonally deciduous forest on limestone outcrops in Central Brazil. Revista Brasileira de Botânica, v. 30, n. 4, p. 611621, out./dez. 2007a.

FELFILI, J. M. et al. Recuperação de matas secas e vegetações associadas no Vale do Paranã, Goiás. Brasília: Universidade de Brasília, Departamento de Engenharia Florestal. 2007b. 32 p.

FELFILI, J. M.; FAGG, C. W. Floristic composition, diversity and structure of the Cerrado sensu stricto on rocky soils in northern Goiás and southtern Tocantins, Brazil. Revista Brasileira de Botânica, v. 30, n. 3, p. 375-385, jul-set. 2007.

HUETE, A. et al. Overview of the radiometric and biophysical performance of the MODIS vegetation indices. Remote Sensing of Environment, v. 83, p. 195-213. 2002.

HURLBERT, A. H.;HASKELL, J. P. The effect of energy and seasonality on avian species richness and community composition. The American naturalist, v. 161, p. 83-97, 2003

IBGE. Instituto Brasileiro de Geografia e Estatística.. Mapa de Vegetação do Brasil. 3. ed. Rio de Janeiro: IBGE, 2004.

LORENZI, H. Árvores Brasileiras. Volume 1. Nova Odessa: Plantarumm, 1998. 368 p.

LORENZI, H. Árvores Brasileiras. Volume 2. Nova Odessa: Plantarumm, 2000. 384 p.

MENESES, P. R; MADEIRA NETTO, J. (Org.). Sensoriamento remoto: reflectância de alvos naturais. Brasília: UnB, Planaltina: Embrapa 
Cerrados, 2001. $262 \mathrm{p}$.

NASA. National Aeronautics and Space Administration. SRTM - Shuttle Radar Topography

Mission. Disponível em : http://www2.jpl.nasa. gov/srtm/costaric.htm . Acesso em 12 de maio de 2008.

NASCIMENTO, A. R. et al. Florística e estrutura da comunidade arbórea de um remanescente de Floresta Estacional Decidual de encosta, Monte Alegre, GO, Brasil. Acta Botanica Brasilica. v. 18, n. 3, p. 659-669. 2004.

NASCIMENTO, A. R. Variações espaciais e sazonais de radiação solar em fragmentos de floresta estacional decidual em afloramento calcário e sua relação com a distribuição de espécies arbóreas. 2005. 143 p. Tese (Doutorado em Biologia)-Universidade de Brasília, Brasília, 2005.

OINDO, B. O.; SKIDMORE, A. K. Interannual variability of NDVI and species richness in Kenya. International Journal of Remote Sensing, v. 23, n. 2, p. 285-298, 2002.
PETTORELLI, N. et al. Using the satellitederived NDVI to assess ecological responses to environmental change. TRENDS in Ecology and Evolution, v. 20, n. 9, Sept. 2005

RIBEIRO, J. F., WALTER, B. M. T. As principais fitofisionomias do bioma Cerrado. In: SANO, S. M.; ALMEIDA, S. P; RIBEIRO, J. F. Cerrado: ecologia e flora. EMBRAPA Cerrados - CPAC Brasília: Embrapa Informação Tecnológica, 2008. 2 v. (1279 p). Cap. 6, 151-212 p.

SAMPAIO, A. B. et al. Regeneration of Seasonal Deciduous Forest Tree Species in Long-Used Pastures in Central Brazil. Biotropica, v. 39, p. 655659. 2007.

SILVA, L. A.; SCARIOT, A. Comunidade arbórea de uma floresta estacional decídua sobre afloramento calcário na bacia do rio Paranã. Revista Árvore, Viçosa, v. 28, n. 1, p. 61-67. 2004.

VIEIRA, D. M.; SCARIOT, A. Principles of Natural Regeneration of Tropical Dry Forests for Restoration. Restoration Ecology. v. 14, n. 1, p. 11-20. 2006.

Ci. Fl., v. 21, n. 1, jan.-mar., 2011 